\title{
Parceria público-privada: um estudo sobre aquisição e investimento em material apostilado para a Educação Infantil da rede pública municipal de ensino - Irati/PR
}

\author{
Public-private partnership: a study on acquisition and investment in \\ handout material for Early Childhood Education in the municipal \\ public-school system - Irati/PR
}

\section{Asociación público-privada: un estudio sobre adquisición e inversión en material-folleto para Educación Infantil en el sistema de escuelas públicas municipales - Irati/PR}

Elisandra Aparecida Czekalski ${ }^{1}$ https://orcid.org/0000-0002-463I-019X Marisa Schneckenberg ${ }^{2}$ https://orcid.org/0000-0002-1825-0097

\begin{abstract}
Resumo: Este trabalho tem como objetivo apresentar e discutir a parceria público-privada entre a Prefeitura Municipal de Irati - PR e a Editora OPET/SEFE, na aquisição de apostilas para a rede pública de ensino do referido município. Como referencial teórico e metodológico para descrição e análise dos dados, o ciclo de políticas foi utilizado. Com o propósito de entender como ocorreu o processo de parceria, foram utilizadas entrevistas com a Secretária Municipal de Educação que atuava na época (200I-2004) da contratação das apostilas (200I). Também, com a Secretária Municipal que atuou no processo de transição da Educação Infantil, em sua perspectiva assistencialista, para a gestão da Secretaria Municipal de Educação, na perspectiva educacional (2005-2009). Ainda, em consulta ao setor administrativo da Prefeitura Municipal, foi possível realizar um levantamento parcial do montante investido pelo município nos dezoito anos da parceria. A conclusão da pesquisa permitiu verificar a urgência das políticas públicas do município discutirem o currículo para a infância com embasamento teórico sólido e pertinente, para que o trabalho pedagógico com os pequenos seja adequado, colocando como premissa primeira o respeito à infância e suas particularidades.
\end{abstract}

Palavras-chave: Educação Infantil. Parceria Público Privado. Apostilas.

Abstract: This work had as aim at presenting and discuss the public-private partnership between the Municipal Administration of Irati - Paraná, in Brazil, and OPET/SEFE publishing company in handout material acquisition to

\footnotetext{
' Mestre em Educação. Professora de Educação Infantil e Pedagoga na rede pública do Município de Irati - PR. UNICENTRO - Campus Irati. Elisandra_czk@hotmail.com

${ }^{2}$ Doutora em Educação. Professora titular do Curso de Licenciatura em Pedagogia e PPGE da UNICENTRO Campus Irati. marisaunicentro@hotmail.com
}

Olhar de professor, Ponta Grossa, v. 24, p. I-23, e-I526I.066, 2021.

Disponível em <https://revistas2.uepg.br/index.php/olhardeprofessor> 
Parceria público-privada: um estudo sobre aquisição e investimento em material apostilado...

the public-school system of the municipality. As theoretical and methodological reference for data description and analysis, the policy cycle was used. To understand how the partnership process has occurred, interviews were used, with the Municipal Secretary of Education who was working at that period (200I-2004) in which the handouts were hired (200I). Also, with the one who worked with the transition process from the Child Education in its supporting perspective to the management of the Municipal Secretariat of Education in its education perspective (2005-2009). Still, in consultation to the management sector of the municipal administration was possible partially survey about the amount invested by the municipality in eighteen years of partnership. In conclusion, the research allowed to verify how urgent the municipal policies are to discuss the syllabus for childhood with solid and pertinent basis, to the pedagogical work with children may occur in the appropriate way, using the respect the childhood and its particularities as the first premise.

Keywords: Child Education. Public-Private partnership. Handout material.

Resumen: Este trabajo tuvo como objetivo presentar y discutir la asociación público-privada entre la Administración Municipal de Irati - Paraná, en Brasil, y la Editora OPET/SEFE, en la adquisición de folletos para la rede pública de enseñanza del referido municipio. Como referencial teórico y metodológico para descripción y análisis de datos, el ciclo de políticas fue utilizado. Con el propósito de entender cómo ha ocurrido el proceso de asociación, fueron utilizadas entrevistas con la Secretaria Municipal de Educación que actuaba en la época (200I-2004) de la contratación de los folletos (200I). También con la Secretaria Municipal que actuó en el proceso de transición de la Educación Infantil, en su perspectiva asistencialista, para la gestión de la Secretaria Municipal de Educación en la perspectiva educacional (2005-2009). Todavía, en consulta al sector administrativo de la Administración Municipal, fue posible realizar un levantamiento parcial de la cantidad invertida por el municipio en los dieciocho años de asociación. La conclusión de la investigación permite comprobar la urgencia de las políticas públicas del municipio discutieren el currículo para la infancia con base teórico sólido y pertinente, para que el trabajo pedagógico con los pequeños sea adecuado, poniendo el respeto por la infancia y sus particularidades como primera premisa.

Palabras clave: Educación Infantil. Asociación Público-Privada. Material en folletos.

\section{Introdução}

Este trabalho, resultado de pesquisa nos estudos em Mestrado em Educação, tem como objetivo apresentar e discutir a parceria público-privada entre a Prefeitura Municipal de Irati - PR e a Editora OPET/SEFE, na aquisição de apostilas para a rede pública de ensino do referido município.

O estudo acima citado tomou o ciclo de políticas como aporte metodológico para sua construção. Destarte, para chegar à discussão acima apresentada, utilizamos os três primeiros contextos do ciclo de política, respectivamente: o contexto de influência, o contexto da produção de texto, e o contexto da prática.

No contexto de influência, realizamos um resgate de cunho bibliográfico acerca das parcerias entre os setores público e privado no campo educacional, enfatizando a aquisição de material didático em forma de apostilas para a educação pública. Desta forma, pudemos verificar como o processo de construção do Estado manteve influência direta na organização, implantação e disseminação das parcerias público-privadas. Também constatamos a influência dos organismos internacionais que, com a abertura do projeto neoliberal, passaram a apresentar propostas para a reforma do setor educacional por meio de agendas, conferências, financiamentos, entre outros.

Ao final do apanhado bibliográfico, consideramos que as implicações dessas parcerias recaem diretamente na não oferta de uma educação de qualidade, pois se pautam em lógicas mercadológicas. 
Logo, tratam os sujeitos que compõem o cenário educacional em meros números e cifras monetárias, assim como interferem diretamente nos processos de democratização da educação.

No contexto da produção de texto, com o intento de afunilar as discussões acerca do currículo para a Educação Infantil, discutimos a relação entre a concepção de infância e de currículo descritos nos documentos nacionais e municipais do município de Irati - PR, versus o modo como o referido município conduz sua ação educativa frente a essas concepções. Arguimos tal questão porque a rede municipal pesquisada destina apostilas do sistema privado de ensino às crianças da Educação Infantil. Em consequência disso, pressupomos que essa escolha deveria constar em suas normativas curriculares, fundamentando, assim, tal decisão.

Para tanto, as contradições averiguadas nos textos das leis municipais denotaram o reflexo de uma sociedade regulada por preceitos neoliberais, que objetivam à privatização da educação. $A$ ação consciente e transformação social, tão enfatizadas na Proposta Curricular Municipal, são ações que a política pública do município não mostra empenho em assegurar, promovendo cada vez mais a reprodução cultural da classe dominante.

Já, nesse excerto se concentram as discussões acerca do terceiro contexto do ciclo de políticas: o contexto da prática. Ball e Bowe (1992 apud MAINARDES, 2006) descrevem que é no contexto da prática que as políticas são interpretadas e recriadas. Uma vez que as políticas se especificam em forma de textos, os leitores nem sempre as interpretam, e nem mesmo a implementam na prática do mesmo modo que a legislação está descrita em textos.

Ao interpretarem os textos das políticas, cada leitor agrega suas experiências, valores e interesses próprios. Isto porque aqueles que formulam os textos políticos não conseguem controlar o significado dado a seus escritos e, assim, fragmentos desses textos serão rejeitados, selecionados, ignorados ou mal-entendidos (BOWE, 1992 apud MAINARDES, 2006).

Neste estudo, pudemos verificar que a interpretação dada pela Secretaria Municipal de Educação, em relação ao processo de inclusão da Educação Infantil à rede pública de ensino, culminou na parceria entre o público e o privado, desencadeando a aquisição de material apostilado para essa etapa da Educação Básica.

Com o propósito de entender como ocorreu esse processo, utilizamos como instrumentos para a pesquisa: entrevistas e a análise de documentos e legislações municipais que orientam a Educação Infantil do município pesquisado. Desta forma, entrevistamos dois personagens distintos: primeiramente, a Secretária Municipal de Educação que atuava na época (200I-2004) da contratação das apostilas (200I); e a Secretária da atual gestão (2017-2020), para entendermos os motivos de sua permanência até os dias atuais. Durante a investigação, constatou-se que a atual Secretária de Educação foi precursora na adoção do sistema apostilado para o município. Porém, no contexto da primeira 
Parceria público-privada: um estudo sobre aquisição e investimento em material apostilado...

parceria, a Educação Infantil ainda era assistida pelo PROVOPAR (Programa Voluntariado Paranaense). Deste modo, consideramos pertinente trazer, também, algumas falas da Secretária Municipal que atuou no processo de mudança na gestão da Educação Infantil, da Secretaria Municipal de Assistência Social para a Secretaria Municipal de Educação.

Consideramos pertinentes as entrevistas com esses atores, uma vez que foi no contexto de sua atuação que a política do currículo prescrito se formalizou. Em outras palavras, foi nesse contexto e por intermédio da gestão municipal que as apostilas passaram a ser usadas por professoras e crianças nas instituições educacionais. Além das entrevistas, em pesquisa junto ao departamento administrativo da Prefeitura Municipal, foi possível constatar parcialmente os valores monetários despendidos pelo município nesses dezoito anos de parceria.

Assim, este escrito se organiza da seguinte forma: inicialmente expomos alguns aspectos educacionais do município pesquisado, que julgamos serem relevantes para melhor situar o contexto em que ocorre o processo da parceria público-privada. Posteriormente, apresentamos o processo e desencadeamento da parceria, assim como os valores investidos pelo município em dezoito anos da contratação de material apostilado da rede privada para a educação pública municipal. Por fim, trazemos os relatos dos personagens responsáveis pela aquisição e implantação das apostilas na rede municipal de ensino.

\section{Características educacionais no município de Irati - PR}

No que concerne aos aspectos educacionais do município, eles estão organizados conforme informações abaixo.

Quadro I- Características educacionais do município de Irati - PR

\begin{tabular}{|l|c|}
\hline Professores efetivos via concurso público & 576 \\
\hline Professores de Educação Infantil efetivos via concurso & 75 \\
\hline Instituições escolares públicas municipais - Ensino & 29 \\
\hline Centros Municipais de Educação Infantil - CMEI & 12 \\
\hline \% de professores com nível superior na rede municipal & $87,3 \%$ \\
\hline Alunos matriculados na rede municipal & 5.430 \\
\hline Crianças matriculadas nos CMEI & 810 \\
\hline
\end{tabular}

Fonte: Organizado pelas autoras com base em informações no site da Secretaria Municipal de Educação, com dados referentes ao ano de 2018.

Atualmente, o município conta com 12 Centros Municipais de Educação Infantil - CMEl que atendem crianças de 0 a 4 anos de idade, que frequentam as unidades em tempo integral ou parcial, 
conforme escolha e necessidade das famílias. A disposição das turmas em relação ao número de crianças por professor cumpre a orientação dada pela Deliberação $N^{\circ}$ 02/14 do Conselho Estadual de Educação do Paraná:

Art. 9. - A organização de grupos infantis deve respeitar as condições concretas de desenvolvimento das crianças e suas singularidades, bem como os espaços físicos, equipamentos e materiais pedagógicos existentes na escola, tendo como parâmetro a seguinte relação professor/criança: I - do nascimento a um ano de idade - até seis crianças por professor; II - de um a dois anos de idade - até oito crianças por professor; III - de dois a três anos de idade - até doze crianças por professor; IV de três a quatro anos de idade - até quinze crianças por professor (PARANÁ, 20I4, p. 03).

As turmas estão divididas sob nomenclaturas conforme a idade: 0 a I ano - Berçário; I a 2 anos - Maternal I; 2 a 3 anos - Maternal II; 3 a 4 anos - Maternal 3. Acima dos 4 anos, as crianças são atendidas nas escolas e estão divididas em: 4 a 5 anos - Pré I; 5 a 6 anos - Pré II. Diante disso, apresentamos um comparativo entre o número de crianças com idade de 0 a 5 anos residentes no município de Irati- PR, versus o número de matrículas na Educação Infantil municipal, tomando como recorte o período entre os anos de 1997 até o ano de 2018.

Tabela 0 I - Comparativo de crianças de 0 a 5 anos residentes versus número de crianças matriculadas

\begin{tabular}{|c|c|c|c|c|}
\hline Ano de referência & $\begin{array}{c}\text { Crianças } \\
\text { residentes de } 0 \\
\text { a } 3 \text { anos }\end{array}$ & $\begin{array}{c}\text { Crianças } \\
\text { residentes de } 0 \text { a } 5 \\
\text { anos }\end{array}$ & $\begin{array}{c}\text { Crianças } \\
\text { matriculadas na } \\
\text { creche }\end{array}$ & $\begin{array}{c}\text { Crianças } \\
\text { matriculadas na } \\
\text { pré-escola }\end{array}$ \\
\hline 1997 & ---- & ---- & ---- & ---- \\
\hline 1998 & ---- & ---- & ---- & ---- \\
\hline 1999 & ---- & ---- & ---- & ---- \\
\hline 2000 & ---- & $4.763^{\prime}$ & ---- & 793 \\
\hline 2001 & ---- & ---- & 570 & 796 \\
\hline 2002 & $1.839^{2}$ & ---- & 587 & 897 \\
\hline 2003 & $1.679^{2}$ & ---- & 626 & 950 \\
\hline 2004 & $1.766^{2}$ & ---- & 684 & 869 \\
\hline 2005 & $|.86|^{2}$ & $3.667^{2}$ & 548 & 875 \\
\hline 2006 & $1.910^{2}$ & $3.659^{2}$ & 768 & 848 \\
\hline 2007 & $1.852^{2}$ & $3.742^{2}$ & 696 & 715 \\
\hline 2008 & $1.820^{2}$ & $3.808^{2}$ & 710 & 699 \\
\hline 2009 & $1.762^{2}$ & $3.655^{2}$ & 574 & 175 \\
\hline 2010 & $1.747^{2}$ & $3.865^{\prime}$ & 479 & 400 \\
\hline 2011 & $1.700^{2}$ & $3.598^{2}$ & 498 & 424 \\
\hline 2012 & $1.730^{2}$ & $3.533^{2}$ & 520 & 410 \\
\hline
\end{tabular}

Olhar de professor, Ponta Grossa, v. 24, p. I-23, e-1526I.066, 2021.

Disponível em <https://revistas2.uepg.br/index.php/olhardeprofessor> 
Parceria público-privada: um estudo sobre aquisição e investimento em material apostilado...

\begin{tabular}{|l|l|l|l|l|}
\hline 2013 & $1.716^{2}$ & $3.524^{2}$ & 482 & 454 \\
\hline 2014 & $1.775^{2}$ & $3.611^{2}$ & 667 & 500 \\
\hline 2015 & $2.099^{2}$ & $3.885^{2}$ & 578 & 988 \\
\hline 2016 & $2.661^{2}$ & $4.485^{2}$ & 668 & 1.297 \\
\hline 2017 & $3.316^{2}$ & $5.197^{2}$ & 716 & 1.327 \\
\hline 2018 & $3.869^{2}$ & $6.038^{2}$ & 737 & 1.230 \\
\hline
\end{tabular}

Fonte: Elaborada pelas autoras com base em informações dos sites do IBGE e INEP/MEC.

'Dados obtidos junto aos censos do IBGE. ${ }^{2}$ Dados obtidos junto ao Cartório de Registro Civil do município de Irati, com base nos registros de certidão de nascimentos daquele cartório ${ }^{3}$.

Observamos, pelas informações acima, que a municipalização do ensino da Educação Infantil se destaca nos dados do Censo Escolar a partir do ano 2000. Anteriormente a esse período, os dados são inexistentes. Percebemos, também, a variante e a diferença de matrículas ano por ano, e a expansão de matrículas na pré-escola a partir do ano de 2015, que ocorre por conta do cumprimento da legislação da obrigatoriedade de matrícula da pré-escola aos 4 anos de idade. Ressaltamos, ainda, a discrepância entre o número de crianças habitantes de 0 a 5 anos e a quantidade delas que tiveram acesso à Educação Infantil na rede pública municipal.

$\mathrm{Na}$ expectativa de alavancar os números de acesso e principalmente a permanência desses estudantes, as políticas públicas educacionais têm estabelecido metas e estratégias para modificar este cenário. Uma dessas políticas concentra-se na definição dos Planos Nacionais, Estaduais e Municipais de Educação.

Os Planos Municipais de Educação (PME) configuram-se em um "instrumento de estado e não de governo. Ele colabora para que as políticas educacionais tenham continuidade para além dos governos" (WERLE; BARCELLOS, 2008, p. 520). Neste sentido, as metas e estratégias ali presentes configuram-se em um documento que deverá ser construído por um conjunto de pessoas da sociedade que, em comum, tem um mesmo objetivo para a comunidade em que o plano foi articulado. Além disso, o PME

Precisa definir metas específicas, a serem concretamente alcançadas a curto, médio e longo prazo pelo município, garantindo a sua identidade e autonomia. Tais metas deverão ser fixadas em prazos menores do que o PNE, constituindo-se não somente um plano, mas um planejamento de um processo dinâmico, que possa efetivamente

\footnotetext{
${ }^{3}$ Ressaltamos que, devido aos dados terem sido adquiridos juntamente ao Cartório de Registro Civil, os números são uma estimativa de crianças residentes no município, pois nem todo registro significa que a criança seja residente na cidade de origem desse registro. Portanto, todo e qualquer cálculo realizado nesta pesquisa acerca do número de crianças residentes e/ou porcentagem de crianças atendidas na Educação Infantil presentes na Tabela 0 I são números aproximados, em razão da falta de um censo anual por parte do IBGE, que impossibilita cálculos precisos.
}

Olhar de professor, Ponta Grossa, v. 24, p. I-23, e-I526I.066, 202 I.

Disponível em <https://revistas2.uepg.br/index.php/olhardeprofessor> 
modificar a realidade até alcançar as metas de longo prazo (SILVA; NOGUEIRA, 20I2, p. 2).

No município de Irati-PR, o PME aprovado pela Lei №3993 de 16 de junho de 2015, com vigência 2015-2025, conta com um total de 20 metas. No que se refere à ampliação do atendimento para crianças na Educação Infantil, o município estabeleceu como meta:

Ofertar até 2016, a educação infantil na pré-escola para crianças de (quatro) a 5 (cinco) anos de idade e ampliar a oferta da educação infantil em CMEls de forma atender no mínimo $50 \%$ (cinquenta por cento) das crianças de 0 (zero) a 3(três) anos da cidade de Irati até o final da vigência deste PME, baseada nas 2.800 crianças do município que possuem esta idade (PME, 2015, p. 44).

Com base nos dados apresentados acima, na tabela 0I, destacamos que o propósito em atender $50 \%$ no ano de 2016 somente alcançou o total de 25,10\% de crianças atendidas. Já no ano de 2017, a porcentagem ficou em $21,59 \%$ de crianças matriculadas; e no ano de 2018 , a porcentagem de crianças atendidas ficou em 19,04\%. O decréscimo das porcentagens se deve ao não aumento do número de vagas nos $12 \mathrm{CMEl}$ existentes, assim como ao aumento considerável da quantidade de crianças na faixa etária dos 0 aos 3 anos.

Umas das estratégias que o município utilizou para que a meta presente no PME para o atendimento de todas as crianças de 4 e 5 anos na pré-escola fosse alcançada não focou a construção de novas escolas, nem na ampliação das que já existiam, mas na transferência das crianças de 4 a 5 anos matriculadas nos CMEI para escolas. Deste modo, muitas dessas crianças transferidas, que usufruíam de suas vagas em período integral nos CMEI, se veem submetidas a frequentar as escolas somente em meio período.

Neste contexto, somos impelidos a questionar as ações dessa política pública em específico. Ofertar a pré-escola para crianças de 4 e 5 anos, com vistas a atender a legislação, significa somente transferi-las de ambiente e ainda condicioná-las a estar nestes locais em período menor, sem levar em consideração a escolha e a necessidade das famílias? Não seria mais prudente, por parte do município, reduzir gastos com a compra de apostilas e investir esse montante na construção de novas unidades e/ou a ampliação de salas nas unidades já existentes?

Do nosso ponto de vista, sim. Seria muito mais sensato o município investir seus recursos públicos em prioridades, principalmente naquelas que visam a atender as reais necessidades de sua população. A construção de ambiente físico que resulta na ampliação de vagas por parte da rede pública é de maior importância frente à aquisição de apostilas para crianças tão pequenas que, neste estágio de desenvolvimento, requerem atividades que considerem muito mais o desenvolvimento amplo, com maior ênfase nas interações e nas brincadeiras do que naquelas que priorizam somente o preenchimento de papéis. 
Parceria público-privada: um estudo sobre aquisição e investimento em material apostilado...

\section{A aquisição de apostilas para a Educação Infantil no município}

O setor privado tem se envolvido cada vez mais nas políticas educacionais públicas, a partir do estabelecimento de acordos entre prefeituras e empresas, sejam elas firmadas por meio de contratos, convênios ou licitações. $O$ fortalecimento dessas parcerias, no campo educacional, abre espaço para que a esfera privada passe a "atuar diretamente na escola pública, no aspecto pedagógico e administrativo, dando margens à questionamentos que atribuem retração do espaço público em detrimento da ampliação do espaço privado" (BELO, 20I4, p. I8I).

No município de Irati - PR, a presença da parceria entre a prefeitura e editoras iniciou, primeiramente, no ano 200I, com a contratação da Editora BASE4, que fornecia, além do material apostilado às crianças, também cursos de formação aos professores que trabalhavam com o material. Mesmo com a mudança de gestão municipal e, respectivamente, das secretárias de educação, a parceria continuou e estende-se até os dias atuais. Neste período, o município firmou parceria com uma única editora que foi, ao longo destes 18 anos, mudando de marca/nome, sendo primeiramente identificada como BASE Editora, que mais tarde alterou o nome para SEFE (Sistema Educacional Família Escola) e, no ano de 2018, a empresa vinculou-se à Editora OPET, combinando seu nome para OPET/SEFE.

Em pesquisa junto ao portal de transparência e com o departamento de administração da Prefeitura Municipal, responsável legal pelo acordo, identificamos que a parceria entre a prefeitura e as editoras ocorre na forma de contrato por licitação, com validade de 12 meses, podendo ser prorrogado por igual período de 12 meses até o limite máximo de 60 meses. Conforme consta nos contratos, esse período de prorrogação foi realizado na maioria deles, eximindo o município de realizar novo pregão/licitação e, neste caso, não sendo possível que outra editora viesse a realizar a parceria. Deste modo, o município segue, há dezoito anos, sendo atendido pela mesma editora.

Em processo de busca por informações junto aos departamentos responsáveis por compras, licitação e pagamentos da prefeitura Municipal de Irati, tivemos resposta somente em nosso terceiro protocolo e, mesmo assim, não tivemos dados de todos os anos que solicitamos. Em resposta oral, o departamento de compras e licitação afirmou não ter conseguido encontrar dados de todos os anos solicitados, cedendo dados dos contratos encontrados gravados em pen drive.

Assim, pudemos constatar a soma anual de recursos públicos em apostilas em apenas alguns anos da parceria. No entanto, esses valores já dão ciência de quanto o município tem dispendido em valores de verba pública desde o ano 2005 na parceria.

\footnotetext{
${ }^{4}$ A identificação da Editora para uso neste trabalho foi aprovada por Parecer Consubstanciado do Comitê de Ética em Pesquisas da Universidade Estadual do Centro Oeste, na data de 07 de junho de 2018.
}

Olhar de professor, Ponta Grossa, v. 24, p. I-23, e-I526I.066, 2021.

Disponível em <https://revistas2.uepg.br/index.php/olhardeprofessor> 
Tabela 02 - Recursos anuais investidos pelo município na aquisição de apostilas

\begin{tabular}{|c|c|c|c|c|c|}
\hline Ano & Editora & $\begin{array}{l}\text { Tipo de } \\
\text { parceria }\end{array}$ & $\begin{array}{l}\text { Custo por aluno da } \\
\text { Educação Infantil }\end{array}$ & $\begin{array}{l}\text { Custo por aluno do } \\
\text { Ensino Fundamental }\end{array}$ & Valor total \\
\hline 2001 & BASE & ---- & ---- & ---- & ---- \\
\hline 2002 & BASE & $\begin{array}{l}--- \\
\end{array}$ & $\begin{array}{ll}--- \\
\end{array}$ & $\begin{array}{l}--- \\
\end{array}$ & $\begin{array}{l}--- \\
\end{array}$ \\
\hline 2003 & BASE & ---- & ---- & ---- & ---- \\
\hline 2004 & BASE & ---- & ---- & ---- & ---- \\
\hline 2005 & BASE & Licitação & 90,00 & ------ & $81.900,00$ \\
\hline 2006 & BASE & ---- & ---- & ---- & ---- \\
\hline 2007 & BASE & ---- & ---- & ---- & ---- \\
\hline 2008 & BASE & ---- & ---- & ---- & ---- \\
\hline 2009 & SEFE & ---- & 140,00 & 170,00 & $119.000,00$ \\
\hline 2010 & SEFE & Licitação & $\begin{array}{c}169,00 * \\
209,00 * *\end{array}$ & ----- & $147.820,00$ \\
\hline 2011 & SEFE & Aditivo $\mathrm{n}^{\circ} \mathrm{I}$ & $* * *$ & $* * *$ & $299.347,00$ \\
\hline 2012 & SEFE & Aditivo $n^{\circ} 2$ & $* * *$ & $* * *$ & $428.255,80$ \\
\hline 2013 & SEFE & Licitação & 193,03 & 298,00 & $383.172,50$ \\
\hline 2014 & SEFE & Aditivo $\mathrm{n}^{\circ} \mathrm{I}$ & $* * *$ & $* * *$ & $425.693,35$ \\
\hline 2015 & SEFE & Aditivo $n^{\circ} 2$ & & & \\
\hline 2016 & SEFE & Aditivo $n^{\circ} 3$ & & & $481.183,00$ \\
\hline 2017 & SEFE & $\begin{array}{c}\text { Licitação/Pregão } \\
\text { 20/2017 }\end{array}$ & $* * *$ & $* * *$ & $1.003 .000,00$ \\
\hline 2018 & OPET/SEFE & $\begin{array}{c}\text { Aditivo } \mathrm{n}^{\circ} \mathrm{I} \\
\text { Contrato } \\
019 / 2017\end{array}$ & $* * *$ & $* * *$ & $1.003 .000,00$ \\
\hline 2019 & OPET/SEFE & $\begin{array}{l}\text { Aditivo } \mathrm{n}^{\circ} 2 \\
\text { Contrato } \\
019 / 2017\end{array}$ & $* * *$ & $* * * *$ & $437.061,20$ \\
\hline
\end{tabular}

Fonte: Elaborada pela autora com base em dados disponíveis no Portal da Transparência da Prefeitura Municipal de Irati e coleta junto ao departamento de administração da prefeitura.

*Valor para apostilas do Infantil I e Infantil 2.

**Valor para apostilas do Infantil 3.

***Não constam nos termos aditivos sobre as tomadas de preços $\mathrm{n}^{\circ} 00 \mathrm{I} / 2010 ; 00 \mathrm{I} / 20 \mathrm{I} 3$; contratos $\mathrm{n}^{\circ}$ $010 / 2010 ; 016 / 2013 ; 019 / 2017$, e valor por aluno, somente valor final do contrato.

****Na renovação do contrato $019 / 2017$ ficaram suprimidos da renovação o material para alunos do $1^{\circ}$ e $2^{\circ}$ ano do Ensino Fundamental, sendo comprado material didático somente para as crianças da Educação Infantil.

Mesmo não tendo todos os valores na íntegra, desde sua implantação em 200I, os dados fornecidos permitem inferir o quanto o município destinou de verba pública para a parceria, que soma um total de $R \$ 4.809 .432,85$ (quatro milhões, oitocentos e nove mil, quatrocentos e trinta e dois reais e oitenta e cinco centavos). Desta forma, este é o montante que o município poderia ter investido na área da educação, seja na construção e/ou ampliação de CMEl, aquisição de acervo bibliotecário, 
Parceria público-privada: um estudo sobre aquisição e investimento em material apostilado...

material pedagógico específico para a Educação Infantil, formação continuada, valorização docente, dentre outras.

O valor despendido pelo munícipio na parceria reforça o quanto os serviços educacionais têm crescido, colocando, inclusive as instituições do setor público como oportunidades de lucro para o setor privado (BALL, 2004). Desta forma, a educação tem se tornado "uma arena de competição de soma zero (em que ninguém ganha sem que outro perca), cheia de atores interessados em si mesmos e em busca de oportunidades" (LARABEE, 1997, apud BALL, 2004, p. I I 20).

Destacamos, ainda, que uma das características do uso de apostilas organizadas de forma padronizada perpetra o engessamento do trabalho docente, onde "o professor perde autonomia, bem como a liberdade de incluir ou excluir conteúdos de acordo com a necessidade e a especificidade da turma" (ANGELO, 2018, p. 18). Sobre a autonomia docente, Marcuse (1979, p. 45, grifo do autor) destaca que:

\begin{abstract}
A autonomia "profissional" anterior do trabalhador era, antes, sua escravização profissional. Mas esse modo específico de escravização era, ao mesmo tempo, a fonte de seu poder específico, profissional de negação - o poder de parar um processo que $\circ$ ameaçava de aniquilamento como ser humano. Agora $\circ$ trabalhador está perdendo a autonomia profissional que o fez membro de uma classe destacada de outros grupos ocupacionais por personificar a refutação da sociedade estabelecida.
\end{abstract}

Se por um lado, o uso de materiais apostilados desencadeia o engessamento e cerceamento da autonomia do professor, a padronização dos conteúdos e atividades presentes no material inserido na rotina pedagógica "remete à manutenção da visão de criança como aluno e, de novo, ao predomínio da importância do material, nesse caso sobre as crianças" (NASCIMENTO, 20I2, p. 74, grifo do autor). Destacamos, ainda, que

[...] em muitas ocasiões pode-se ouvir políticos e autoridades educacionais defendendo a implantação de sistema apostilados de ensino em suas cidades, pois seria assegurado que $o$ aluno da escola $x$ possuísse a mesma aprendizagem da escola y. [...] a padronização é tida como asseguradora da qualidade de ensino. E o discurso vai além. Não só todas as escolas municipais teriam um padrão de qualidade entre si, mas também seriam elevadas por meio da utilização das apostilas a um patamar nunca atingido por escolas públicas; ou seja, estariam em pé de igualdade com as instituições particulares (AMORIM, 2008, p. I43).

Esse discurso, de foco igualitário salvacionista que a aquisição dos sistemas apostilados proporciona, remete à fetichização da apostila, como se ela fosse capaz de "desfazer as desigualdades sociais impostas pela defasagem cultural das classes carentes" (AMORIM, 2008, p. 178). Em outras palavras,

A apostila é, deste modo, uma forma de conhecimento enlatado, pois assim como o alimento, evita o contato como o objeto em natura, ou seja, impede que o indivíduo tenha contato com a cultura real. A cultura que chega até os educandos por meio

Olhar de professor, Ponta Grossa, v. 24, p. I-23, e-I526I.066, 202 I.

Disponível em <https://revistas2.uepg.br/index.php/olhardeprofessor> 
das apostilas é fragmentada, industrializada, pasteurizada e filtrada. Os alunos e professores tendem - em especial nas realidades mais desprovidas de recursos - a ficar à mercê de uma única fonte de informações [...] a cultura enlatada oferecida pelas apostilas torna-se, portanto, uma semicultura, semiformando indivíduos, que, iludidos, creem serem emancipados e autônomos (AMORIM, 2008, p. 180).

Amorim (2008) destaca, ainda, que os gestores municipais, ao se comprometerem com contratos que destinam o fornecimento de um material gráfico igualitário, entendem que toda a educação municipal terá acesso a uma mesma educação, pautada em conteúdos iguais, mas se esquecem de que os ambientes e as condições de vida dessas crianças são os mais diferentes possíveis.

\section{O que dizem as gestoras municipais em relação à adoção de apostilas para a Educação Infantil}

Vai já pra dentro, menino! Vai já pra dentro estudar!

É sempre essa lengalenga quando o que eu quero é brincar...

Eu sei que aprendo nos livros, eu sei que aprendo no estudo, mas o mundo é variado

[...] Se eu me fecho lá em casa, numa tarde de calor, [...] Como eu vou saber da chuva se eu nunca me molhar? Como eu vou sentir o sol, se eu nunca me queimar? Como eu vou saber da terra, se eu nunca me sujar? [...]eu quero aprender o mundo!

(Pedro Bandeira) $^{5}$

Tomamos como ponto de partida para a discussão desta seção um excerto da poesia de Pedro Bandeira, que tão bem representa o desejo das crianças, a expectativa de uma vivência, um anseio ao natural, de descobrir um mundo que é repleto de conhecimento, mas que, muitas vezes, lhe é privado. $O$ adulto quer que ele aprenda pelos livros, pelo estudo, e se esquece de que há muito mais que aprender, e nem tudo do mundo cabe ou está presente nos livros.

Estas linhas poéticas, em muitos leitores, soam como notáveis lembranças de sua infância; para outros há indiferença a elas, tão importantes experiências. É com esta discrepância de sentimentos, de

\footnotetext{
5 BANDEIRA, Pedro. Mais respeito, eu sou criança. 2 ed. São Paulo: Moderna, 2002.
} 
Parceria público-privada: um estudo sobre aquisição e investimento em material apostilado...

visões de quais caminhos e experimentos as crianças devam viver em sua infância que levantamos a problemática: Por que os municípios têm adquirido cada vez mais sistemas de ensino privados para a Educação Infantil, insistindo em oferecer às crianças experiências escolarizadas, e as têm privado de viver a poesia na prática?

Cabe ressaltar que pensamos e defendemos, aqui, a mesma visão de autores como Rocha, Lessa e Buss-Simão (2016) e Carvalho $(2016)^{6}$, pois não somos contra a formação com base nos saberes historicamente acumulados, nem contra aqueles advindos dos campos de experiência, como propõe a BNCC. Somos contrários à antecipação e utilização de atividades desenvolvidas por crianças dos anos iniciais do Ensino Fundamental, somos contrários à escolarização precoce que ocorre nos ambientes da Educação Infantil, à (pré)paração para os anos iniciais, à utilização de apostilas que trazem pouca ou nenhuma experiência genuinamente infantil, atividades que não convidam a explorar o mundo, que não aguçam verdadeiramente os sentidos de ouvir, ver e sentir plenamente.

Elas limitam a apenas olhar a chuva das janelas, sem oferecer o prazer em contemplá-la, sentir suas gotas tocando seu corpinho, sem sentir o cheiro da terra que vai, aos poucos, ficando molhada, sem permitir sujar-se em uma poça de lama. Elas se restringem a demonstrar a metamorfose da borboleta somente em imagens, e não incentivam a construir um borboletário, mesmo pequeno, em vidros.

Uma educação tão e somente emparedada e voltada ao estudo com preenchimento de papéis, sem a possibilidade da experiência real e ativa, não há de dar conta do complexo mundo de possibilidades e descobertas da infância.

Para poder entender o contexto e processo de adoção de material apostilado na educação municipal de Irati - PR, consideramos pertinente realizar entrevista com o representante legal da Secretaria Municipal de Educação. Neste caso, foi realizada entrevista com a Secretária Municipal de Educação que instituiu a parceria, e que depois de dezoito anos assumiu a Secretaria pela segunda vez, sendo a Secretária atual.

Vale ressaltar que, no processo de pesquisa, constatou-se que a implementação da parceria ocorreu no ano de 200 l e, naquele período, a gestão da Educação Infantil do município de Irati - PR era de responsabilidade do PROVOPAR (Programa Voluntariado Paranaense). A Secretaria Municipal de Educação assumiu a gestão da Educação Infantil somente no ano de 2007, ou seja, seis anos depois do início da parceria. Deste modo, é de interesse e importância histórica coletar e registrar os relatos

\footnotetext{
${ }^{6}$ Ver mais em CARVALHO, R. S. O investimento na formação do cidadão do futuro: a aliança entre economia e educação infantil como estratégia de governamentalidade contemporânea. Educação em Revista, Belo Horizonte, v. 32, n. 2, p. 229-253, abr./jun. 2016.
}

ROCHA, E. A. C.; LESSA, J. S.; BUSS-SIMÃO, M. Pedagogia da infância: interlocuções disciplinares na pesquisa em educação. Da investigação às práticas, Lisboa, v. 6, n, I, p. 31-49, jan./mar. 2016. 
de ambas as Secretárias Municipais, tanto a que institui a parceria, quanto a que assumiu a Educação Infantil em 2007.

Neste interim, por meio do depoimento de ambas, procuramos conhecer um pouco sobre o processo de adoção das apostilas e a permanência delas até o presente momento. Seguindo orientações para preservação da identidade das Secretárias de Educação, utilizamos as siglas SI e S2 como identificação nas entrevistas.

Para poder entender todo esse contexto de implantação de sistema apostilado e de transição da assistência social para a Educação, o qual é bastante rico de informações, sintetizamos em quadro uma linha do tempo com o período das gestões municipais e os fatos ocorridos, e que turmas recebiam apostila em cada gestão municipal.

Quadro 2 - Linha do tempo da parceria

\begin{tabular}{|c|c|c|}
\hline Gestão/Período & $\begin{array}{c}\text { Orgão/Secretaria responsável pela Educação Infantil- Fatos } \\
\text { históricos }\end{array}$ & $\begin{array}{l}\text { Turmas/Séries que } \\
\text { utilizavam as } \\
\text { apostilas }\end{array}$ \\
\hline $200 I-2004$ & $\begin{array}{l}\text { PROVOPAR - Em 200I ocorre o início da parceria entre a } \\
\text { Prefeitura Municipal de Irati - PR e a Editora BASE. }\end{array}$ & $\begin{array}{l}\text { Educação Infantil e } \\
\text { Ensino Fundamental }\end{array}$ \\
\hline $2005-2008$ & $\begin{array}{l}\text { Até } 2007 \text { PROVOPAR, em } 2008 \text { inicia a transição de } \\
\text { responsabilidade para a Secretaria Municipal de Educação. }\end{array}$ & Educação Infantil \\
\hline $2009-2012$ & $\begin{array}{l}\text { Em } 2009 \text { ocorre o primeiro concurso para Professor de } \\
\text { Educação Infantil no município. }\end{array}$ & Educação Infantil \\
\hline $2013-2016$ & $\begin{array}{l}\text { Em } 2016 \text { inicia, no município, a obrigatoriedade de matrícula } \\
\text { das crianças de } 4 \text { anos, e transferência das crianças dos CMEI } \\
\text { para as escolas municipais. }\end{array}$ & $\begin{array}{l}\text { Educação Infantil e } \\
\text { Anos iniciais do } \\
\text { Ensino Fundamental }\end{array}$ \\
\hline $2017-2020$ & $\begin{array}{l}\text { Quatro anos de vigência do Plano Municipal de Educação, e a } \\
\text { prospecção de atendimento de } 50 \% \text { de crianças de } 0 \text { a } 3 \text { anos } \\
\text { nos CMEl ainda não se concretiza. }\end{array}$ & $\begin{array}{l}2017 \text { e } 2018 \text { = } \\
\text { Educação Infantil e } \\
\text { Anos iniciais do } \\
\text { Ensino Fundamental. } \\
\text { Em 2019 voltou a ser } \\
\text { utilizado somente } \\
\text { pela } \\
\text { Infantil. }\end{array}$ \\
\hline
\end{tabular}

Fonte: Elaborado pelas autoras com base nas entrevistas com as Secretárias Municipais de Educação, 2019.

As entrevistas com as Secretárias Municipais sobre o processo de implementação e continuidade da parceria entre a Prefeitura Municipal e as Editoras ocorreram de forma amistosa, e possibilitaram realizar um importante resgate histórico da Educação Infantil municipal. Tal resgate permite que ela não seja esquecida, mas conhecida principalmente pela comunidade.

Sabíamos da existência de uma parceria entre o público e o privado no município investigado, mas não sabíamos qual a origem dela. Assim, nosso primeiro questionamento à SI foi sobre como ocorreu o processo de implementação de apostilas no município. Seu relato informa que: 
Parceria público-privada: um estudo sobre aquisição e investimento em material apostilado...

Em 200I, em uma outra gestão, quando fui convidada para ser Secretária, e já nos anos 2000, quando assumimos, estávamos formando a equipe juntamente com o PROVOPAR e, na época, o PROVOPAR era no mesmo prédio, [e] foi nos apresentado esse material. Então, reunimos a equipe que iria trabalhar comigo para analisar o material. Visto que era uma novidade e que nós, eu conhecia simplesmente o Positivo, que meus filhos eram adolescentes e estudavam no Positivo, o outro já estava na faculdade. Eu achei maravilhoso, porque vinha ao encontro com a Proposta Pedagógica do município, porque se falava muito nisso, da Proposta Pedagógica, e a do Positivo fugia um pouco da nossa proposta, porque seria uma apostila mais técnica e nós não queríamos muito isso, queríamos uma mais humanizada. E gostamos muito, e o prefeito acolheu essa ideia e fez o contrato. Então nós fizemos o contrato para - Pré porque as creches pertenciam ao PROVOPAR, e ficamos até 2004, final da nossa gestão, e foi muito bem aceito (SI, grifo nosso).

Vemos, no relato da SI, que o material apostilado era uma novidade para a educação pública no contexto da implantação, no ano $200 \mathrm{I}$. A preocupação da gestão era de que o material adquirido tivesse a mesma linha da Proposta Curricular Municipal. Tendo feito a análise do material, o contrato foi realizado pela Prefeitura e, embora a Secretária não tenha relatado a participação da comunidade docente na escolha do material, ela afirma que ele foi bem aceito.

Cabe ressaltar que, naquele contexto da análise e implantação da parceria, existia uma apreensão em adquirir um material que dialogasse com a Proposta Curricular Municipal. No entanto, ressaltamos que as crianças que receberam as apostilas atendidas nas creches assistidas pelo PROVOPAR ainda não dispunham de Proposta Curricular específica para a Educação Infantil, pois a Proposta Curricular para a Educação Infantil foi elaborada somente a partir do ano 2008, quando a Secretaria Municipal de Educação passou a assumir a Educação Infantil. Mesmo assim, o documento elaborado em 201 I não fez menção ao uso de sistemas privados de ensino por parte da educação na rede pública de ensino municipal.

Fica explícita, aqui, a construção de políticas não normativas e/ou não oficiais, ou seja, aquelas que não estão prescritas nos textos oficiais das políticas em forma de legislação e/ou outras orientações legais (BALL; MAGUIRE; BRAUN, 2016).

Verificamos, ainda, que o corpo docente não foi ouvido na/para a escolha do material didático que eles passariam a usar. Isto fica evidente na fala da secretária que atuou na transição da Educação Infantil da área assistencial para a educação, pois as professoras não utilizavam o material nas escolas. Diante disso, destacamos a fala da SI sobre a aceitação do material por parte da classe docente: ela afirma que 'ele foi bem aceito'. Assim, quando ouvimos a S2, ela assegurou que as apostilas não eram utilizadas no ambiente escolar e, deste modo, em sua gestão (2005-2012), houve a continuidade da parceria, porém com alterações.

Claro que ali envolve muito o financeiro na época. Então, na época (2005), os primeiros anos do Ensino Fundamental tinham os livros, só que a gente sabia que,

Olhar de professor, Ponta Grossa, v. 24, p. I-23, e-1526I.066, 2021.

Disponível em <https://revistas2.uepg.br/index.php/olhardeprofessor> 
do ensino fundamental, os professores não estavam utilizando os livros, que eu saía de dentro da escola, eu via esses livros nas prateleiras, porque o professor não se identificava, não gostava daqueles conteúdos, [...] a gente fez, também, né, no Ensino Fundamental, foi uma pesquisa com os professores, se o material seria válido ou não, e os professores estavam trabalhando mais com o livro didático que vinha do Ministério da Educação, eles gostavam mais daquele material. Então a gente, daí, já em 2005, deixou só na Educação Infantil mesmo (S2, grifo nosso).

É imprescindível destacar esta situação da não aceitação das apostilas por parte dos professores, e não questionarmos: se não era usado, é porque não foi aceito. $E$, se não foi aceito, porque assim mesmo continuou sendo adquirido? A escolha culminou na aplicação de recursos públicos, que poderiam ter sido aplicados em outras perspectivas na área educacional do município, mas isto não ocorre.

Além disso, a S2 justifica que estava na escola e que viu o não uso, e mesmo fazendo parte de outra gestão administrativa, e tendo este feedback, poderia ter dado encerramento ao contrato, mas ela deu continuidade. Deste modo, questionamos S2 sobre qual foi a motivação/justificativa para esse prosseguimento.

\begin{abstract}
Quando a gente entrou na secretaria de educação, já vinha sendo ofertado o material para as crianças, até para o município vinha sendo bom, porque não era só comprar os livros, a agendinha para as crianças, vinha todo o apoio didático para o professor, livro do professor, vinha os CDs, para ele conduzir os temas do livro. Então, tudo isso já vinha sendo feito, a gente não quis cortar, tirar. [...] no infantil, como os professores não tinham material específico, pouco material de acesso, também nós, assumindo toda aquela faixa etária, a secretaria também, meio despreparada para esse suporte para os professores, e a gente concluiu que, se continuasse tendo a continuidade do material, a gente estaria até ofertando um ensino de melhor qualidade. E apoiando, também, lá na base, os professores com $\circ$ material didático, porque eles também tiveram a capacitação do que veio, né, que fazia parte desse projeto de colocar o sistema de ensino na Educação Infantil (S2, grifo nosso).
\end{abstract}

O relato da $\$ 2$, sobre as justificativas para continuidade da parceria, fornece várias informações. A primeira questão apontada concentra-se na oferta da cesta de serviços pela editora que, para o município, era algo bastante conveniente, pois não demandava trabalho extra com formação para os professores. Isto porque a própria editora realizava cursos de capacitação e, além disso, o kit vinha acompanhado de material de apoio para o professor, de como desenvolver as atividades em sala.

A segunda questão seria o fato de o município estar assumindo a Educação Infantil naquele momento, e a falta de uma equipe preparada para dar suporte abriu espaço para a continuidade da parceria, facilitando o trabalho da equipe gestora. A intenção final, destacada pela S2, seria a oportunidade de estar ofertando um ensino de melhor qualidade para as crianças.

Ainda segundo a S2, a continuidade do trabalho com material apostilado na gestão de 20052012 contemplou somente a Educação Infantil, pois após efetuar pesquisa junto aos professores do 
Parceria público-privada: um estudo sobre aquisição e investimento em material apostilado...

Ensino Fundamental, chegou-se à conclusão de que o material adquirido via parceria não estava sendo utilizado nas escolas. Então optou-se, naquele momento, pelo encerramento da utilização de apostilas pelos professores e alunos do Ensino Fundamental.

Tendo a informação de que as professoras não participaram da análise, nem mesmo da escolha das apostilas, a nós interessava saber quem foram os personagens que participaram dessa apreciação e opção do material para posterior apresentação ao gestor municipal. Segundo relatos da SI, participaram desta análise:

A equipe pedagógica da Secretaria Municipal de Educação e algumas professoras colegas, que atuavam no curso de pedagogia, e que dariam um maior suporte, se as apostilas realmente eram tudo aquilo que eles estavam falando (SI).

Percebemos que a análise do material ocorreu na colaboração entre a equipe gestora da rede municipal e alguns professores que atuavam no curso de Pedagogia. Esta cooperação demonstra uma interação positiva entre diferentes setores educacionais. No entanto não vemos, no relato, a presença de nenhum representante do corpo docente municipal no processo de avaliação do material.

Por mais que a equipe pedagógica fosse formada por docentes da rede municipal, a opinião dos professores no momento de avaliação das apostilas é de fundamental importância, pois são eles que estarão na ponta dessa implantação, trabalhando diariamente com a apostila. Assim eles poderiam, antes mesmo de firmar a parceria, verificar possíveis falhas existentes, ter escolhido o material de outra editora, ou até mesmo confrontado a parceria. A adoção do sistema de ensino configurou-se, portanto, em um processo verticalizado, no qual os professores da rede não participaram efetivamente com direito à opinião e, sobretudo, com direito à interferência.

Sabemos que nenhuma parceria inicia sem um motivo, uma justificativa, e muitos desses argumentos têm a ver, também, com a visão sobre o produto que está envolvido nesses contratos. Questionamos, ainda, a SI se, na visão dela, a apostila é um recurso válido para a Educação Infantil.

Eu acredito, né, porque, pense: se eu não acreditasse, eu não dava continuidade. Embora a situação financeira dos municípios agora é outra, a situação financeira dos Estados, do Brasil é outra, e então nós não temos mais condições financeiras de optar por este livro até o quinto ano (SI).

Embora as orientações para o trabalho com a Educação Infantil enfatizem outros vieses, o relato da SI demonstra que sua leitura segue outra perspectiva, ao acreditar que o uso de material apostilado é válido para essa etapa da educação, pois, do contrário, não teria investido na contratação.

Já em diálogo com a S2, ela relatou o que pensa a respeito do uso de material apostilado na Educação Infantil.

Olhar de professor, Ponta Grossa, v. 24, p. I-23, e-1526I.066, 2021.

Disponível em <https://revistas2.uepg.br/index.php/olhardeprofessor> 
Eu acho assim, que é válido, também, a apostila na Educação Infantil, mas esse material, tudo depende de como o professor vai conduzir o trabalho, porque não pode ficar preso só naquele conteúdo da apostila. Então, o professor depende da criatividade, do empenho, da vontade do professor de ir além do que a apostila apresenta, né (S2).

O relato da S2 demonstra que ela tem uma leitura ampliada do trabalho pedagógico com a criança pequena, pois, apesar de acreditar na validade do uso de apostila na Educação Infantil, ela entende que o professor não deve ficar preso a somente este uso e a este recurso. No entanto, para que isso ocorra, são necessários empenho e criatividade do professor. Ressaltamos, aqui que, a depender da qualidade dos cursos de formação continuada, eles podem colaborar muito na construção de um trabalho pedagógico diversificado e criativo.

De um modo geral, os discursos das Editoras, ao oferecerem seus produtos aos municípios, estão embasados principalmente na oferta de apoio à gestão. Deste modo, indagamos a SI, em que a parceria colabora na gestão da Secretaria Municipal de Educação.

Hoje a parceria é muito boa para a Educação Infantil, com todo o Ensino Fundamental. Quando vêm as formações, essas formações, os nossos professores estão na frente de muitos municípios, porque eu tenho ido em reuniões, que estão ainda estudando como que vão se organizar com a nova BNCC, e os nossos professores, coordenadores e diretores já tiveram formação lá em agosto, da BNCC. $E$ isso se deve a essa parceria desse material. Senão, eu teria que contratar uma pessoa, trazer para cá, quem sabe até o valor seria o que a gente paga pelo pacote... Então, [há] o crescimento da equipe, que também participa. Ficam atualizados, porque eles sempre trazem novidades da educação. Porque a educação é dinâmica, está mudando dia a dia, os nossos professores, nossos coordenadores e equipe da secretaria estão bem atualizados (SI, grifo nosso).

Vemos, neste relato, um ponto positivo da parceria: a formação ofertada pela editora. Esta formação, de certa forma, acaba por colocar os professores da rede municipal à frente de professores de outros municípios.

Contudo, se analisarmos o trecho da fala acima, "Senão, eu teria que contratar uma pessoa, trazer para cá, quem sabe até o valor seria o que a gente paga pelo pacote"(SI), e resgatarmos os valores

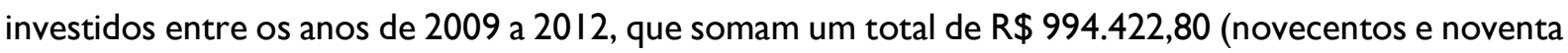
e quatro mil, quatrocentos e vinte e dois reais e oitenta centavos), temos certeza de que, se fossem contratados cursos de formação continuada aos docentes no mesmo período, o montante seria bem menor, e dando ainda a possibilidade de investir o saldo em outras despesas da área da educação.

É interessante ressaltar que, neste processo histórico da parceria, dos anos $200 \mathrm{I}$ até 2008, a Educação Infantil era assistida pelo PROVOPAR, e ainda não havia ocorrido a transição da Secretaria Municipal de Assistência Social para a Secretaria Municipal de Educação. Porém, as turmas do pré, crianças com 5 e 6 anos, que estavam alocadas nas creches, utilizavam o material apostilado que era adquirido pela Secretaria de Educação. Segundo relato da SI, isso se deve ao fato de que o PROVOPAR 
Parceria público-privada: um estudo sobre aquisição e investimento em material apostilado...

não recebia verba específica para esse fim, e a Secretaria era parceira deles, por isso a prefeitura cedeu, além dos recursos humanos, também as apostilas.

Para além da validade do uso de material apostilado pelas crianças, questionamos a S2 se ela acredita que esse uso auxilia ou não no trabalho docente.

Eu acho que auxilia, sim, principalmente quando vem um professor que está ingressando na carreira, né. Ele vem assim, com muitas ideias, mas, se ele tiver um ponto de apoio, um material, então ele vai direcionar o trabalho dele, né, ele vai ter uma visão já do que deve ser trabalhado, de acordo com aquela faixa etária da criança (S2).

No que se refere ao uso de material apostilado na condição de auxílio ou não no trabalho do professor, a S2 diz acreditar que a adoção de apostila ajuda o professor no desenvolvimento do seu trabalho, pois atua como um ponto de apoio, do que deve ser trabalhado em devida faixa etária.

Neste contexto, recordamos que, além das DCNEI, há uma Proposta Curricular municipal que elenca toda uma grade de conteúdo, sobre o que deve ser dado ênfase nas atividades pedagógicas com as crianças da Educação Infantil. $O$ que ambas as orientações curriculares não propõem são as atividades práticas em si. No entanto, a depender da criatividade e empenho do professor, as atividades elaboradas por eles podem ser muito mais atraentes que as propostas nas apostilas.

Se o uso da apostila na Educação Infantil é um recurso válido principalmente para os docentes, pois orienta o trabalho pedagógico, questionamos a $\$ 2$ se este uso é um recurso válido para as crianças.

Sim, é um recurso válido, sim. Eles gostam de ter um material, eles querem ter uma mochila, eles querem ter um livro, porque eles veem os irmãos mais velhos, muitas vezes, e eles ficam muito faceiro[s], muito feliz[es] quando eles dizem: esse é o meu livro! Muitos chamam de apostila, mas muitos dizem assim, porque até quando nós implantamos, a própria instituição que forneceu o sistema de ensino pro município falou de livro, eles falavam que não devia chamar de apostila, para valorizar até mais para a criança, para ela ver que ela também tem um material, também tem um livro. Ela se identifica com aquele material, e a criança gosta de folhear, de sentir, de perceber. Então eu acho válido, mas tudo vai depender de como o professor conduzirá seu trabalho (S2).

A perspectiva da S2 novamente remete a validade à forma de condução do trabalho docente. No que concerne se o uso é válido, a secretária relaciona a validade mais pelo sentimento de pertencimento que a criança tem sobre o material, do que pela validade cognitiva que pode vir a ter na proposta de suas atividades.

Destacamos que as crianças podem folhear, sentir, perceber, não somente uma apostila, mas diversos tipos de livros, quais sejam: livros de literatura simples, cartonados, emborrachados, revistas, e até mesmo um caderno de artes que contenha atividades derivadas de suas próprias construções diárias.

Olhar de professor, Ponta Grossa, v. 24, p. I-23, e-15261.066, 2021.

Disponível em <https://revistas2.uepg.br/index.php/olhardeprofessor> 
Já a visão da SI sobre a validade do uso de apostilas na rede pública de ensino é descrita da seguinte forma:

Eu sempre trabalhei com todos os níveis de ensino. Como eu era professora de Pedagogia, eu estava dentro das escolas municipais, e uma das disciplinas que eu tinha era Prática Pedagógica, e que eu tinha que ir nos estágios, e eu sentia a dificuldade dessas alunas, e as minhas alunas de Pedagogia eram professoras municipais. E durante as aulas, elas se queixavam muito que o livro que vinha do ministério da Educação, ele não dava um suporte para o ano todo, tinha muitas falhas, que até hoje todos têm. Então eu já tinha um pensamento de elaborar pelo menos um material. Quando chegou esse material, meu Deus, ele já estava pronto, né, e nós fomos acompanhando, no primeiro ano, para ver se era bem aceito, e foi resistente, sempre o que é novo é resistente. Então, o primeiro ano foi resistente, a secretaria tinha que fazer visitas mais periódicas sobre o uso do material, porque tinha escolas que deixavam no armário. Quando chegava a equipe, eles corriam e iam usando o material. No segundo ano foi bem melhor. Quando nós saímos, em 2004, já estavam bem adaptadas. Então, a continuidade deve-se, não sei, porque não era eu, ao fato de que foi muito bem aceito. Então, em 200I, ele foi caminhandinho, engatinhando, em 2002, já andando, e 2004 já estavam adaptadas e não queriam largar mais esse material, fizeram até pedido para que o próximo prefeito e próxima secretária continuasse (SI, grifo nosso).

Vemos, neste relato, a contradição do que a SI expõe acima, sobre a aceitação do material apostilado pela classe docente municipal. Evidencia-se a resistência do grupo frente à adoção do material, e principalmente a coerção que os professores sofriam por não estarem utilizando as apostilas. Isso só reforça a crença de que se a comunidade docente fosse ouvida antecipadamente, a parceria certamente não teria ocorrido.

Além disso, há a notável dubiedade de anseios e de solicitações, de alunas que faziam parte do quadro do magistério municipal, que se queixavam da insatisfação dos livros didáticos encaminhados pela esfera federal, e gostariam de algo diferente, mas que, ao mesmo tempo, em um primeiro momento, apresentaram certa resistência ao um novo material. $O$ que nos faz pensar: mas afinal de contas, o que essas professoras almejavam?

Enquanto pesquisadores, e como não estava em nosso roteiro, não ouvimos as vozes dessas professoras para saber seus motivos em não usar o material, e nem quais os motivos de uma parcela ser resistente à utilização das apostilas.

\section{Considerações finais}

O percurso traçado ao longo desta pesquisa, tendo como foco principal a adoção e o uso de material apostilado do setor privado pela Educação Infantil da rede municipal, permitiu verificar a urgência das políticas públicas do município discutirem seriamente o currículo para a infância com 
Parceria público-privada: um estudo sobre aquisição e investimento em material apostilado...

embasamento teórico sólido e pertinente, para que o trabalho pedagógico com os pequenos seja adequado, colocando como premissa primeira o respeito à infância e suas particularidades.

A implantação de legislação e documentos oficiais nacionais, estaduais e municipais não assegura a autonomia das instituições educacionais, ocasionando uma sucessão de concepções de criança e infância inadequadas. Justamente os personagens mais prejudicados são aqueles que fazem a educação acontecer cotidianamente, os docentes, seguidos pelas crianças, que recebem uma educação que não é a que gostariam de ter, mas, lamentavelmente, é a que lhes oferecem.

Voltando à reflexão inicial, que levou a debruçar-nos sobre este estudo, constatamos que o motivo específico para firmar a parceria em $200 \mathrm{l}$ ocorreu na visita da Editora ao município e apresentação das apostilas aos gestores municipais. Em um primeiro momento, podemos afirmar que esta parceria ocorreu mais por pura curiosidade de como seria o trabalho com o material apostilado, mesmo que essa decisão não tivesse dado espaço diretamente aos professores.

Esta escolha, em não ouvir os docentes na decisão e definição das apostilas, desencadeou resistência ao seu uso pelas professoras que lecionavam nas escolas municipais, como afirmado no relato da S2. No entanto, mesmo vendo tal situação, a parceria teve continuidade, ora estando presente somente nos CMEI, ora estando presente em escolas e CMEI.

Em nenhum momento ouviu-se a voz das professoras, em nenhuma ocasião, nestes dezoito anos de parceria, observou-se a heterogeneidade das escolas, a realidade de cada instituição escolar, muito menos a diversidade cultural das crianças. Simplesmente lhes é oferecido um currículo homogêneo, estreito, empobrecido, na evidente e existente deficiência de experiências que as apostilas oferecem. Escolariza-se e empareda-se cada vez mais cedo crianças, pensando tão e somente na pedagogia do exame: pensa-se mais em construir números e menos em construir humanos.

Isto não se evidencia somente nas políticas de nível local. Os objetivos propostos nas conferências nacionais e mundiais do campo da educação têm sempre a intenção de alcançar números. Porém, nem sempre traçar objetivos para a qualidade da educação se concentra somente em elencar números, principalmente se estes números miram apenas a qualificação de mão de obra para o mercado de trabalho, como adestramento, e a educação não é vista como sinônimo de direito, de crescimento pessoal, como meio de inserir-se na sociedade como cidadão.

Deste modo, fica evidente que o município ainda não encontrou o fio da meada da cultura da infância nos espaços educativos que, baseada no Ensino Fundamental, acaba por trazer seus moldes para dentro da Educação Infantil: crianças sentadas, emparedadas, que insiste em não seguir à risca o que contempla o Projeto Político Pedagógico - PPP, quando este fala em limitar a atividades aleatórias, repetitivas, de cópia; que se extinga a apostila, porque ela vai de encontro a tudo isso. Nortear-se em estudos que colocam a criança como ser social que possui história e, na prática, implementar outra 
realidade acaba com a autonomia dos CMEI que, mesmo tendo construído suas propostas, não as seguem. Desta forma, mais uma vez a construção do PPP não passa de processo meramente burocrático.

Mudar este cenário? Há, sim, possibilidades de isso ocorrer. Para tanto, é necessário, antes, que as lideranças políticas e gestoras coloquem esses sujeitos como protagonistas da escolha e elaboração de suas políticas. Dar vez e voz a elas é apenas um dos primeiros passos a ser dado. Um segundo seria atualizar leituras, buscar outros campos de pesquisas sobre a infância.

Não é somente querer copiar isto ou aquilo que deu certo em outro contexto, mas de ver além disso. De perceber que criança é criança, seu desenvolvimento biológico é o mesmo, seja aqui, na Finlândia ou no Chile. Certamente a curiosidade e vontade de aprender e descobrir o mundo também são. $O$ que falta é olhar verdadeiramente para ela, levar em consideração aquilo que todos nós, adultos, já sabemos, já vivemos, mas que, infelizmente, muitas vezes, nos esquecemos.

E se isso não for muito, lembremos mais uma vez de Pedro Bandeira (2002, p. II) “[...] lá no seu tempo de infância, será que não foram felizes? Mas se tudo o que fizeram já fugiu de sua lembrança, fiquem sabendo o que eu quero: mais respeito, eu sou criança!"

Respeito: palavra-chave que deve ser considerada na construção de currículos para a Educação Infantil. Respeito à faixa etária, ao seu tempo e espaço, às suas vontades, desejos e sonhos. Nunca limitar experiências, não ceifar suas cem formas de ver, ouvir, sentir e aprender sobre o mundo.

\section{Referências}

AMORIM, I. F. de. Reflexões críticas sobre os sistemas apostilados de ensino. 2008.

Dissertação (Mestrado em Educação) - Universidade Estadual Paulista, Araraquara, 2008. Disponível em: https://repositorio.unesp.br/handle/l I449/903।4 Acesso em: 12 mar 2018.

ANGELO, J. de S. D. Sistema apostilado e Educação Infantil: o ensino como negócio. 2018. Tese (Doutorado em Educação) - Pontifícia Universidade Católica, São Paulo, 20I8. Disponível em: https://tede2.pucsp.br/handle/handle/2 I 309 Acesso em: 3I abr 2019.

BALL, S. J. Performatividade, privatização e pós-Estado do Bem-Estar. Educação e Sociedade, Campinas, v.25, n.89, p.I I05-I I26, set./dez. 2004. Disponível em:

http://www.scielo.br/pdf/es/v25n89/226I3.pdf. Acesso em: 04 jul. 2019.

BALL, S. J.; MAGUIRE, M.; BRAUN, A. Fazendo Pesquisa sobre atuação de políticas. In: BALL, S. J.; MAGUIRE, M.; BRAUN, A. Como as Escolas fazem políticas. Tradução de Janete Bridon. Ponta Grossa: Editora UEPG, 2016, p. II-34.

BANDEIRA, P. Mais respeito, eu sou criança. Ed. Moderna. 2002.

BELO, F. F. A lógica do mercado na educação pública municipal: a parceria públicoprivada em Catalão/Goiás. 20I4. Tese (Doutorado em Educação) - Universidade Federal de 
Parceria público-privada: um estudo sobre aquisição e investimento em material apostilado...

Goiás, Goiânia, 2014. Disponível em: https://repositorio.bc.ufg.br/tede/handle/tede/3528 Acesso em: 10 mai 2019.

CARVALHO, R. S. O investimento na formação do cidadão do futuro: a aliança entre economia e educação infantil como estratégia de governamentalidade contemporânea. Educação em Revista, Belo Horizonte, v. 32, n. 2, p. 229-253, abr./jun. 2016. Disponível em: https://www.scielo.br/j/edur/a/J5hsXCwbDCKzxR5H4xGh7Qr/abstract/?lang=pt Acesso em: 10 abr 2019.

IRATI. Lei n 3993 de 16 de junho de 20 I5. Aprova o Plano Municipal de Educação. Disponível em: https://silo.tips/download/plano-municipal-de-educaao-6 Acesso em: 10 mar 2018.

MAINARDES, J. Abordagem do ciclo de políticas: uma contribuição para a análise de políticas educacionais. Educação e Sociedade. Campinas, vol. 27, n. 94, p. 47-69, jan./abr. 2006. Disponível em: http://www.scielo.br/pdf/es/v27n94/a03v27n94.pdf. Acesso em: 04 mai. 2019.

MARCUSE, H. A ideologia da sociedade industrial. Tradução: Giasone Rebuá. $5^{a}$ edição. Rio de Janeiro: Zahar Editores, 1979.

NASCIMENTO, M. L. B. P. As políticas de educação infantil e a utilização de sistemas apostilados no cotidiano de creches e pré-escolas públicas. Revista Brasileira de Educação. São Paulo. v. 17. n. 49, jan./abr. 2012. Disponível em: http://www.scielo.br/pdf/rbedu/v17n49/a03vl7n49.pdf. Acesso em: 06 mai 2019.

PARANÁ. Deliberação Nº2/l 4 do Conselho Estadual de Educação do Paraná. Dispõe sobre Normas e Princípios para a Educação Infantil no Sistema de Ensino do Estado do Paraná. Disponível em: http://www.cee.pr.gov.br/arquivos/File/pdf/Deliberacoes/20I4/Del_02_I4.pdf. Acesso em: 0 I dez. 20 I 9.

SILVA, S. R. de A.; NOGUEIRA, S. M. de A. O Plano Municipal de Educação no contexto do desenvolvimento local e da cultura da escola. In: V Simpósio Internacional sobre a Juventude Brasileira, 2012, UFPE (Pernambuco). Anais UFPE. Disponível em http://www.anpae.org.br/IBERO_AMERICANO_IV/GTI/GTI_Comunicacao/ScheilaRibeiroDeAbreuE Silva_GTI_integral.pdf. Acesso em: 06 maio 2019.

ROCHA, E. A. C.; LESSA, J. S.; BUSS-SIMÃO, M. Pedagogia da infância: interlocuções disciplinares na pesquisa em educação. Da investigação às práticas, Lisboa, v. 6, n, I, p. 3 I-49, jan./mar. 2016. Disponível em: https://repositorio.ipl.pt/handle/l0400.2 I/6435 Acesso em: 31 mar 2019.

WERLE, F. O. C.; BARCELLOS, J. A. S. Plano Municipal de Educação e a afirmação de princípios para a educação local. Ensaio: Avaliação e Políticas Públicas em Educação, Rio de Janeiro, v. I6, n. 6I, p. 5I5-542, out/dez. 2008. Disponível em: http://www.scielo.br/pdf/ensaio/vl6n6l/vl6n6la03.pdf. Acesso em: 01 mai. 2019.

Olhar de professor, Ponta Grossa, v. 24, p. I-23, e-1526I.066, 2021. 
Recebido em: 02 de maio de 2020.

Versão corrigida recebida em: 12 de março de 202।.

Aceito em: 12 de março de 2021 .

Publicado online em: 26 de junho de 2021.

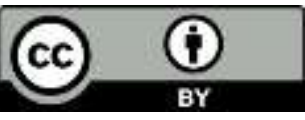

